\title{
Availability and use of personal protective equipment and satisfaction of healthcare professionals during COVID-19 pandemic in Addis Ababa, Ethiopia
}

Wakgari Deressa $^{1 *}$ (D, Alemayehu Worku', Workeabeba Abebe ${ }^{2}$, Muluken Gizaw ${ }^{1}$ and Wondwossen Amogne ${ }^{3}$

\begin{abstract}
Background: Healthcare professionals (HCPs) are at the frontline in the fight against COVID-19 and are at an increased risk of becoming infected with coronavirus. Risk of infection can be minimized by use of proper personal protective equipment (PPE). The aim of this study was to assess the availability and use of PPE, and satisfaction of HCPs with PPE in six public hospitals in Addis Ababa, Ethiopia.

Methods: A cross-sectional study was conducted among 1134 HCPs in June 2020. A systematic random sampling and consecutive sampling techniques were used to select the study participants. Data were collected using a selfadministered questionnaire. Descriptive statistics were used to describe the data and Chi-square test was used to assess the association between the groups. Bivariate and multivariable logistic regression models were used to assess factors associated with satisfaction of healthcare workers.

Results: The mean $( \pm$ SD) age of the participants was $30.26 \pm 6.43$ year and $52.6 \%$ were females. Nurses constituted about $40 \%$ of the overall sample, followed by physicians (22.2\%), interns $(10.8 \%)$, midwives $(10.3 \%)$ and others (16.7\%). The majority (77\%) of the HCPs reported that their hospital did not have adequate PPE. A critical shortage of N95 respirators was particularly reported, it only increased from 13 to 24\% before and during COVID-19, respectively. The use of N95 increased from 9 to 21\% before and during COVID-19, respectively. Almost 72\% of the respondents were dissatisfied with the availability and use of PPE in their hospital. The independent predictors of the respondents' satisfaction level about PPE were healthcare workers who reported that PPE was adequately available in the hospital (adjusted $\mathrm{OR}=7.65,95 \% \mathrm{Cl}: 5.09-11.51$ ), and preparedness to provide care to COVID-19 cases (adjusted OR $=2.07,95 \% \mathrm{Cl}: 1.42-3.03$ ).

Conclusions: A critical shortage of appropriate PPE and high level of dissatisfaction with the availability and use of PPE were identified. Therefore, urgent efforts are needed to adequately supply the healthcare facilities with appropriate PPE to alleviate the challenges.
\end{abstract}

Keywords: Coronavirus, COVID-19, Ethiopia, Healthcare professionals, PPE, SARS-COV-2, Satisfaction

\footnotetext{
* Correspondence: deressaw@gmail.com

'Department of Preventive Medicine, School of Public Health, College of

Health Sciences, Addis Ababa University, Addis Ababa, Ethiopia

Full list of author information is available at the end of the article
}

(C) The Author(s). 2021 Open Access This article is licensed under a Creative Commons Attribution 4.0 International License, which permits use, sharing, adaptation, distribution and reproduction in any medium or format, as long as you give appropriate credit to the original author(s) and the source, provide a link to the Creative Commons licence, and indicate if changes were made. The images or other third party material in this article are included in the article's Creative Commons licence, unless indicated otherwise in a credit line to the material. If material is not included in the article's Creative Commons licence and your intended use is not permitted by statutory regulation or exceeds the permitted use, you will need to obtain permission directly from the copyright holder. To view a copy of this licence, visit http://creativecommons.org/licenses/by/4.0/ The Creative Commons Public Domain Dedication waiver (http://creativecommons.org/publicdomain/zero/1.0/) applies to the data made available in this article, unless otherwise stated in a credit line to the data. 


\section{Background}

The outbreak of coronavirus disease 2019 (COVID-19), caused by the severe acute respiratory syndrome coronavirus 2 (SARS-CoV-2), has been declared as a pandemic by the World Health Organization (WHO) on the 11th of March 2020 [1]. Worldwide, the pandemic has caused over 189 million cases and more than four million deaths as of 15th July 2021 [2]. The African continent has the lowest number of globally confirmed cases, standing roughly at 6,129,805 and registering 155,149 deaths. As of 15th July 2021, Ethiopia has confirmed 277,318 COVID-19 cases, 4349 deaths, and 262,167 recoveries from over 2.9 million tests performed to date, with $9.4 \%$ test positivity. At the moment, Ethiopia stood at 5 th from Africa in terms of the reported number of confirmed COVID-19 cases next to South Africa (1st), Morocco (2nd), Tunisia (3rd) and Egypt (4th). Thus far the case fatality rate of Ethiopia, which represents $1.6 \%$ of the cumulative confirmed COVID-19 cases, is less than the average for Africa (2.5\%) and the world (2.2\%). Nonetheless, recent reports from the country suggest a spiking rate of coronavirus transmission in the community [3].

Healthcare professionals (HCPs) are at the frontline of defense in combating COVID-19 and they play a critical role, not only in the management of COVID-19 patients, but also in ensuring adequate infection prevention and control (IPC) measures in healthcare settings. As a result, they are at a substantially increased risk of becoming infected with the virus and could potentially contribute to the transmission [4-6]. In Ethiopia, over 1311 health workers have contracted coronavirus as of 17th September 2020. About 11\% of HCPs retrospectively studied in Spain had COVID-19 [7]. Early evidence from countries with the highest mortality rates of COVID-19 indicates that healthcare workers are considerably at greater risk of being infected with coronavirus ranging from 15 to $20 \%$ of the infected population and are therefore at a disproportionate risk to the rest of the population $[8,9]$. For instance, the Italian Regional Reference Laboratories reported that healthcare workers accounted for $10 \%$ of 162,000 cases of COVID-19 in the country [10]. Similarly, the US Centers for Disease Control and Prevention reported that healthcare workers accounted for about 11\% of all confirmed COVID-19 cases in the United States [11].

Infection prevention and control (IPC) measures such as the use of appropriate PPE, proper handwashing, and hand hygiene are critical in preventing the transmission and risk of infection of COVID-19 in healthcare settings. The use of appropriate PPE by healthcare workers in particular during the current COVID-19 pandemic is highly recommended and the national and international safety protocols for healthcare workers should be strictly followed $[1,12,13]$. Since the initial outbreak report of COVID-19 in China in December 2019, there has been an increasing demand for PPE globally. In many healthcare settings particularly in Africa HCPs have limited access to appropriate PPE to protect their health in many healthcare settings [6]. As a result, many healthcare workers remain concerned about the risk of infection from the SARS-COV-2 due to the shortage of appropriate PPE recommended by WHO, and they have become ill-equipped to care for patients with COVID-19 or other causes, due to acute shortage of appropriate PPE [13].

A lack of PPE puts both HCPs and patients at risk of contracting coronavirus infection. It also presents many HCPs with challenging decisions about whether to care and provide treatment for COVID-19 patients in the absence of effective PPE. On the other hand, the number of COVID-19 cases is rising and the shortages in PPE remain a major concern. The purpose of this study was to assess the availability and use of PPE as well as satisfaction level of HCPs practicing in public hospitals in Addis Ababa during the current COVID-19 pandemic.

\section{Methods}

\section{Study area and setting}

A hospital-based cross-sectional study was conducted from 9th to 26th June 2020 at six public hospitals in Addis Ababa city administration, three months after the first confirmed COVID-19 case in Ethiopia in March 2020. Addis Ababa city is the most populated urban city in Ethiopia, with a projected population of about 3.6 million in 2019 [14]. There were 12 hospitals and close to 100 health centers belonging to the public center, and about 25 private hospitals in Addis Ababa. Addis Ababa city has the highest rate of COVID-19 cases and deaths in Ethiopia [15]. The hospitals selected for the current study were the leading hospitals in the country and provided outpatient and inpatient services for the city residents and patients coming from different parts of the country.

\section{Study population and sampling}

Of the 12 government hospitals in Addis Ababa city administration, the following six were purposively selected based on the relatively higher number of health work forces: Tikur Anbessa Specialized Hospital (TASH), Zewditu Memorial Hospital (ZMH), Ghandi Memorial Hospital (GMH), Menelik II Hospital (MH), Yekatit 12 Hospital Medical College (Y12HMC) and St. Paul Hospital Millennium Medical College (SPHMMC). The study population included all categories of HCPs practicing in the selected hospitals at the time of the survey. In this study, HCP is defined as a healthcare provider in the selected hospital involved in the provision of healthcare services including intern doctors, resident doctors, 
general practitioners, medical specialists and subspecialists, health officers, anesthetists, nurses, midwives, laboratory technologists, radiologists, pharmacists, physiotherapists, X-ray and laboratory technicians. The study targeted the HCPs since they are the majority involved in a number of healthcare activities which render them at risk of acquiring and transmitting infections.

Sample size was calculated using a single crosssectional study design formula based on a $50 \%$ prevalence estimate of the availability of PPE in the hospital at 95\% confidence level, $4 \%$ precision, a design effect of 1.5 and $25 \%$ non-response rate. Accordingly, the minimum total sample size targeted for this survey was 1200 respondents. A mix of purposive and random sampling was applied to select participants based on their availability and willingness to participate in the study. In each hospital, the types and number of wards were initially identified and the number of healthcare workers within each ward was obtained from the human resource department. The sample size allocated to the hospital was distributed to the wards proportional to the size of their healthcare workers. Since it was difficult to obtain the complete list of healthcare workers in each ward at the time of the study, proper random sampling was not followed to select the study participants. Some healthcare workers in particular physicians or nurses were on duty, some were working in different departments in the same hospital or another hospital, and others were reluctant to accept the invitation to participate in the study. The list of the available voluntary healthcare workers was obtained and a simple random sampling was applied to select potential respondents based on the sample size allocated to each ward. All eligible participants who consented to participate were recruited into the study.

\section{Data collection}

Date were collected using structured paper-based selfadministered questionnaires that composed of sections on demographic and occupational characteristics of the respondents (e.g., gender, age, education and years of work experience), working unit, availability and practices regarding compliance with usage of PPE (gloves, gowns, facemask, N95 respirator, goggles, face shields, and hair covers), as well as their main concerns and worries about the availability and use of proper PPE during the current COVID-19 pandemic (Additional file 1). The satisfaction level of HCPs regarding the availability and use of PPE included four items: (1) I am satisfied with the current availability of PPE in my hospital during the COVID-19, (2) I am satisfied with the current use of PPE by health professionals in my hospital, (3) I am satisfied that the correct PPE (as recommended by WHO) is always available to me when managing suspected or confirmed COVID-19 patient in my hospital, and (4) I am satisfied that the correct PPE (as recommended by WHO) is always available to me when treating nonCOVID-19 patients in my hospital. These items were measured using a five-point Likert scale, where 1strongly dissatisfied, 2-dissatisfied, 3-average, 4-satisfied, and 5-strongly satisfied. The internal consistency of the questionnaire was measured by Cronbach's alpha coefficient, and the Cronbach's alpha for the satisfaction level was 0.769 .

The survey questionnaire was developed in English based on related literature and available national and international PPE guidelines. It was also administered in English since the medium of instruction in Ethiopia particularly in high schools and universities is in English. A total of 12 experienced data collectors with health backgrounds were involved in data collection. One data collector per hospital was independently recruited and trained for this purpose, while one assistant healthcare workers was recruited from each hospital to facilitate and assist the data collection process. A guideline was developed by the research team to guide the data collectors, assistant healthcare workers and supervisors for data collection, quality assurance of data and ethical conduct during implementation of the survey (Additional file 2). The components of the guidelines included sections on selection of respondents, data collection procedures using self-administered questionnaire, and ethical issues including COVID-19 infection prevention measures. Training and orientation on the survey including how to administer the questionnaire were conducted for the data collectors using webinar.

Before handing out the questionnaires to the potential study participants in the selected hospitals, the data collectors introduced themselves to the respondents, build a rapport with them and explained the aims of the study and data collection procedures. After obtaining consent from the participants, the questionnaires were handed out to the respondents and appointed for return to recollect the completed questionnaires. The questionnaires were distributed with a cover letter (consent form), introducing the study and explaining the purpose of the survey, instructions on how to complete the questionnaire, and researchers contact information for any questions the respondent might have. Participants completed the questionnaires by themselves in English language. Data collection took place concurrently in all hospitals. Upon return of the questionnaires, the data collectors checked for completeness and consistency, and incomplete questionnaires were taken back to the respondents for completion as much as possible.

\section{Statistical analyses}

Before data entry, each questionnaire was checked for completeness. Data were entered into the Census 
Surveys Professional (CSPro) Version 7.2 statistical software package and subsequently exported to SPSS version 23.0 (IBM SPSS Statistics for Windows, Armonk, NY: IBM Corp., 2015, USA) for cleaning and data analysis. Continuous data were summarized using means and standard deviations, while categorical data were presented as frequency counts and percentages. Descriptive statistics were used to describe the study variables. The Chi-square test was used to assess the association between the groups.

The overall satisfaction score regarding the availability and use of PPE for each respondent was calculated by taking the sum of the scores of the four questions. Responses to these questions were summed to form a total satisfaction score ranging from 4 to 20 , with higher scores indicating higher level of satisfaction. Using the total satisfaction score of the four items, study participants were classified into two groups: dissatisfied $(<12$ scores) and satisfied ( $\geq 12$ scores). A bivariate and multivariable binary logistic regression were performed to identify the main factors associated with HCP's satisfaction level regarding availability and use of PPE. Individuals were classified into two groups based on their satisfaction level: satisfied group (1), and the rest were placed in the dissatisfied group (0). Odds ratios (ORs) and their 95\% confidence intervals (CIs) were used to quantify the associations between the outcome variable (satisfaction level) and potential predictors (gender, medical profession, working unit, hospital, whether received training in PPE during the COVID-19 pandemic, whether used any 'homemade' or 'creative' PPE during COVID-19, whether they reported that adequate PPE was available to protect them from risk of infection while managing suspected/confirmed COVID-19 patients, and preparedness to tackle COVID-19). A value of $P<0.05$ was used for all the statistical significance tests.

\section{Results}

\section{Sample characteristics}

From a total of 1247 HCPs approached in six hospitals, 1228 consented to participate in the study and received the questionnaires, while 19 did not accept the invitation. Of 1146 completed and returned questionnaires, 12 were discarded due to missing data, resulting in 1134 (91\%) valid questionnaires for analysis. About 53\% were females. Among the respondents reporting age, the mean $( \pm$ SD) age was $30.3 \pm 6.4$ years, about $58 \%$ aged between 20 and 29 years, and $32 \%$ aged $30-39$ years (Table 1). The largest number of respondents were from TASH $(25 \%, n=283)$ and SPHMMC $(20.5 \%, n=233)$, followed by ZMH $(15.6 \%, n=177)$ and MH $(15.3 \%, n=$ 174). Nurses constituted about $40 \%$ of the overall study participants, followed by physicians (22.2\%), interns
(10.8\%) and midwives (10.3\%). Among 252 physicians (22.2\%) participated in the study, GPs and resident doctors accounted for 44.8 and $42.9 \%$, respectively, while specialists and sub-specialists consisted the remaining $12.3 \%$. With OB/GYN department constituting $17.2 \%$ of the respondents, surgical (13.9\%), pediatrics (13.1\%), medical (13.0\%) and OPD (10.5\%) departments represented a fairly similar number of study participants. Among the study participants reporting work experience, about 49 and $25 \%$ of the respondents reported that they served in the hospital less than 5 years and 5-9 years, respectively. However, the majority of the respondents $(67 \%)$ at SPHMMC only served less than 5 years as compared to $28.3 \%$ of their counterparts at TASH.

\section{Availability of PPE before and during COVID-19}

The HCPs were asked the types of PPE that were frequently available in the hospital before and during the COVID-19 pandemic. Table 2 shows the self-reported availability of different PPE by HCPs before and during the COVID-19. Gloves and gowns were reported as the most frequently available PPE in the routine care of patients before and during the pandemic. During the COVID-19 pandemic, the frequently available PPE as reported by the study participants has improved, for example, the frequent availability of surgical facemask and N95 respirator has increased from 59.3 and $12.6 \%$ before the pandemic to 82.6 and $24.2 \%$ during the pandemic, respectively. The self-reported availability of gloves before and during COVID-19 was $>90 \%$ for all hospitals except SPHMMC, and no statistically significant difference was observed between the availability of gloves before and during COVID-19. The availability of gowns for all the study hospitals was $>60 \%$ before and during the COVID-19, with no significant increase during the COVID-19.

The availability of facemask and N95 respirator showed a statistically significant increase during COVID-19 as compared to the pre-COVID-19 $(P<$ 0.001 ). Similarly, the availability of eye protection (goggles and face shield) has increased from $18.6 \%$ before the pandemic to $27.1 \%$ during the pandemic $(P<0.001)$, but a steady increase was observed in the availability of hair covers during the pandemic as compared with the time before COVID-19 $(P=0.240)$. This study found a major variation among the study hospitals with regard to the frequently available PPE before and during COVID-19. The frequent availability of N95 respirator during the pandemic was reported by $36 \%$ of the participants from SPHMMC and 30\% from TASH as compared with 9.2\% at $\mathrm{MH}$ and $13 \%$ at $\mathrm{GMH}$. Even simple hand sanitizer was in short supply in some hospitals as reported by some respondents. 
Table 1 Characteristics of study participants by hospital

\begin{tabular}{|c|c|c|c|c|c|c|c|}
\hline \multirow[t]{2}{*}{ Characteristics } & \multicolumn{6}{|c|}{ Hospital, n (\%) ${ }^{a}$} & \multirow{2}{*}{$\begin{array}{l}\text { Total, } \mathbf{n} \\
\text { (\%) }\end{array}$} \\
\hline & TASH & ZMH & GMH & Y12HMC & $\mathrm{MH}$ & SPHMMC & \\
\hline \multicolumn{8}{|l|}{ Gender $(n=1134)$} \\
\hline Male & $140(49.5)$ & $72(40.7)$ & $42(36.5)$ & $67(44.1)$ & $90(51.7)$ & $126(54.1)$ & $537(47.4)$ \\
\hline Female & $143(50.5)$ & $105(59.3)$ & $73(63.5)$ & $85(55.9)$ & $84(48.3)$ & $107(45.9)$ & $597(52.6)$ \\
\hline \multicolumn{8}{|c|}{ Age group (years) $(n=982)$} \\
\hline $20-29$ & $83(42.8)$ & $98(60.9)$ & $55(51.4)$ & $69(46.6)$ & $98(62.0)$ & $166(77.6)$ & $569(57.9)$ \\
\hline $30-39$ & $85(43.8)$ & $46(28.6)$ & $33(30.8)$ & $60(40.5)$ & $48(30.4)$ & $45(21.0)$ & $317(32.3)$ \\
\hline$\geq 40$ & $26(13.4)$ & $17(10.6)$ & $19(17.8)$ & $19(12.8)$ & $128(7.6)$ & $3(1.4)$ & $96(9.6)$ \\
\hline Mean $( \pm \mathrm{SD})$ & $32.6( \pm 7.1)$ & $30.1( \pm 6.8)$ & $31.8( \pm 7.3)$ & $31.7( \pm 6.0)$ & $29.5( \pm 5.8)$ & $27.0( \pm 4.0)$ & $30.3( \pm 6.4)$ \\
\hline \multicolumn{8}{|c|}{ Professional category $(n=1134)$} \\
\hline Physician & $79(27.9)$ & $39(22.0)$ & $17(14.8)$ & $35(23.0)$ & $39(22.4)$ & $43(18.5)$ & $252(22.2)$ \\
\hline Intern & $17(6.0)$ & $36(20.3)$ & $7(6.1)$ & $12(7.9)$ & $29(16.7)$ & $22(9.4)$ & $123(10.8)$ \\
\hline Nurse & $128(45.8)$ & $54(30.5)$ & $51(44.3)$ & $48(31.6)$ & $68(39.1)$ & $104(44.6)$ & $453(39.9)$ \\
\hline Midwife & $19(6.7)$ & $15(8.5)$ & $21(18.3)$ & $15(9.9)$ & $20(11.5)$ & $27(11.5)$ & $117(10.3)$ \\
\hline Other ${ }^{\mathrm{b}}$ & $40(14.1)$ & 33 (18.6) & $19(16.5)$ & $42(27.6)$ & $18(10.3)$ & $37(15.9)$ & $189(16.7)$ \\
\hline \multicolumn{8}{|c|}{ Department/Unit ( $n=1134)$} \\
\hline OB/GYN & $20(7.1)$ & 35 (19.8) & $56(48.7)$ & $22(14.5)$ & $33(19.0)$ & $29(12.4)$ & $195(17.2)$ \\
\hline Surgical & $50(17.7)$ & $16(9.0)$ & 0.0 & $14(9.2)$ & $28(16.1)$ & $49(21.0)$ & $157(13.8)$ \\
\hline Pediatrics & $25(8.9)$ & $24(13.6)$ & $5(4.3)$ & $35(23.0)$ & $25(14.4)$ & $37(15.9)$ & $151(13.3)$ \\
\hline Medical & $44(15.6)$ & $31(17.5)$ & 0.0 & $27(17.8)$ & $28(16.1)$ & $17(7.3)$ & $147(13.0)$ \\
\hline OPD/Screening/Triage & $41(14.5)$ & $17(9.6)$ & $16(13.9)$ & $21(13.8)$ & 19 (10.9) & $30(9.0)$ & $144(12.7)$ \\
\hline Emergency & $35(12.4)$ & $9(5.1)$ & $10(8.7)$ & $10(6.6)$ & $10(5.7)$ & $21(9.0)$ & $95(8.4)$ \\
\hline Anesthesia/OR/IC & 39 (13.8) & $13(7.3)$ & $14(12.2)$ & $5(3.3)$ & $6(3.4)$ & $16(6.9)$ & $93(8.2)$ \\
\hline Other ${ }^{c}$ & $28(9.9)$ & $32(18.1)$ & $14(12.2)$ & $18(11.8)$ & $25(14.4)$ & $34(14.6)$ & $151(13.3)$ \\
\hline \multicolumn{8}{|c|}{ Work experience $(n=938)$} \\
\hline$<5$ & $80(42.1)$ & $88(57.1)$ & $49(45.0)$ & $76(59.4)$ & $103(68.2)$ & $156(75.7)$ & $552(58.8)$ \\
\hline $5-9$ & $81(42.6)$ & $39(25.3)$ & $40(36.7)$ & $42(32.8)$ & $32(21.2)$ & $44(21.4)$ & $278(29.6)$ \\
\hline $10-14$ & $16(8.4)$ & $17(11.0)$ & $8(7.3)$ & $5(3.9)$ & $11(7.3)$ & $4(1.9)$ & $61(6.5)$ \\
\hline $15-34$ & $13(6.8)$ & $10(6.5)$ & $12(11.0)$ & $5(3.9)$ & $5(3.3)$ & $2(1.0)$ & $47(5.0)$ \\
\hline Total, n (\%) & $283(25.0)$ & 177 (15.6) & 115 (10.1) & $152(13.4)$ & $174(15.3)$ & $233(20.5)$ & $1134(100)$ \\
\hline
\end{tabular}

${ }^{\mathrm{a}}$ TASH Tikur Anbessa Specialized Hospital; ZMH Zewditu Memorial Hospital; GMH Ghandi Memorial Hospital; Y12HMC Yekatit 12 HospitalMedical College; MH Menelik II Hospital; SPHMMC St. Paul Hospital Millennium Medical College.

b Other: Includes anesthetist, pharmacist, health officer, lab technologist and radiographer

'Other: Includes Isolation room/ward, Pharmacy, Oncology, etc.

\section{Use of PPE before and during COVID-19}

The HCPs were asked the types of PPE that were frequently used in the hospital before and during the COVID-19 pandemic. Table 3 presents the self-reported frequently used PPE by HCPs before and during COVID-19. Gloves and gowns were identified as the most frequently used PPE in the hospital before and during the COVID-19 pandemic. The use of gloves by all HCPs was above 90\%, while the self-reported use by other healthcare workers before and during COVID-19 was relatively lower than others, despite showing some improvement during COVID-19. Likewise, the self-reported use of gowns was not different before and during the pandemic, whereas its selfreported use rate remained less than $80 \%$ for the different categories of HCPs. The self-reported frequent use of surgical facemask has increased from $47.2 \%$ before the pandemic to $85.7 \%$ during the pandemic for all HCPs $(P<0.001)$.

The self-reported frequent use of N95 respirator has also increased from $9.1 \%$ before the pandemic to $21.2 \%$ during the pandemic $(P<0.001)$. Similarly, the use of eye protection (goggles and face shield) has increased from $11.6 \%$ before the pandemic to $22.4 \%$ during the pandemic $(P<0.001)$. A statistically significant increase in the percentage of respondents reporting the frequent 
Table 2 Frequently available PPEs by hospital before and during COVID-19 $(n=1134)$

\begin{tabular}{|c|c|c|c|c|c|c|}
\hline \multirow[b]{2}{*}{$\begin{array}{l}\text { Frequently } \\
\text { available } \\
\text { PPE by } \\
\text { hospital } \\
\text { before and } \\
\text { during } \\
\text { COVID-19 }\end{array}$} & \multicolumn{6}{|c|}{ Frequently available PPE, \% } \\
\hline & Glove & Gown & Facemask & N95 respirator & Eye protection & Hair cover \\
\hline \multicolumn{7}{|c|}{ TASH $(n=283)^{a}$} \\
\hline Before & 92.9 & 73.5 & 77.4 & 23.3 & 21.6 & 19.1 \\
\hline During & 93.3 & 70.3 & 86.9 & 30.0 & 27.2 & 20.8 \\
\hline$P$-value & 0.868 & 0.400 & $<0.001$ & 0.071 & 0.117 & 0.559 \\
\hline \multicolumn{7}{|c|}{ ZMH $(n=177)$} \\
\hline Before & 96.6 & 65.5 & 59.3 & 5.1 & 14.7 & 11.3 \\
\hline During & 95.5 & 67.2 & 83.1 & 16.9 & 22.0 & 19.8 \\
\hline$P$-value & 0.586 & 0.736 & $<0.001$ & $<0.001$ & 0.074 & 0.028 \\
\hline \multicolumn{7}{|c|}{ GMH $(n=115)$} \\
\hline Before & 97.4 & 76.5 & 67.8 & 3.5 & 25.2 & 21.7 \\
\hline During & 96.5 & 76.5 & 87.8 & 13.0 & 33.9 & 19.1 \\
\hline$P$-value & 0.701 & 1.00 & $<0.001$ & 0.008 & 0.149 & 0.624 \\
\hline \multicolumn{7}{|c|}{ YHMC $(n=152)$} \\
\hline Before & 92.8 & 84.9 & 42.1 & 12.5 & 11.8 & 13.2 \\
\hline During & 92.1 & 82.9 & 87.5 & 28.9 & 15.1 & 13.8 \\
\hline P-value & 0.828 & 0.640 & $<0.001$ & $<0.001$ & 0.401 & 0.867 \\
\hline \multicolumn{7}{|c|}{$\mathrm{MH}(n=174)$} \\
\hline Before & 93.1 & 73.0 & 48.3 & 5.7 & 8.6 & 6.9 \\
\hline During & 90.8 & 67.8 & 76.4 & 9.2 & 12.1 & 6.9 \\
\hline$P$-value & 0.431 & 0.291 & $<0.001$ & 0.221 & 0.291 & 1.00 \\
\hline \multicolumn{7}{|c|}{ SPHMMC $(n=233)$} \\
\hline Before & 92.3 & 63.5 & 52.3 & 15.0 & 26.6 & 21.9 \\
\hline During & 87.1 & 61.8 & 76.0 & 36.1 & 46.4 & 23.2 \\
\hline$P$-value & 0.067 & 0.702 & $<0.001$ & $<0.001$ & $<0.001$ & 0.721 \\
\hline \multicolumn{7}{|c|}{ All hospitals $(n=1134)$} \\
\hline Before & 93.8 & 72.0 & 59.3 & 12.6 & 18.6 & 16.0 \\
\hline During & 92.2 & 70.0 & 82.6 & 24.2 & 27.1 & 17.9 \\
\hline$P$-value & 0.118 & 0.309 & $<0.001$ & $<0.001$ & $<0.001$ & 0.240 \\
\hline
\end{tabular}

${ }^{a}$ TASH Tikur Anbessa Specialized Hospital; ZMH Zewditu Memorial Hospital; GMH Ghandi Memorial Hospital; YHMC Yekatit 12 Hospital Medical College; MH Menelik II Hospital; SPHMMC St. Paul Hospital Millennium Medical College.

use of hair covers during the pandemic as compared with the time before COVID-19 was also reported $(P=0.008)$. The self-reported use of N95 respirator was the highest for physicians before $(15.9 \%)$ the pandemic, followed by nurses (9.1\%). The least selfreported use of N95 respirator before (3.3\%) and during (13\%) the pandemic was reported by interns. Overall, the self-reported use of N95 respirator was lower than other PPE except the use of hair cover. Although there was an increase in the self-reported use of hair cover during the pandemic, its use was generally very low and the difference was not statistically significant regarding its use by the different categories of HCPs.

With regard to the types of PPE used during their last interaction with any patient in the hospital, the majority of the HCPs reported the use of gloves (91.2\%), gowns (72.4\%), and facemasks (86.8\%), with about 24, 19 and $18 \%$ reporting N95 respirator, eye protection and hair dresses, respectively (Table 4).

\section{Satisfaction level of healthcare professionals about PPE} Table 5 shows the satisfaction level of HCPs with regard to the current availability and use of PPE in the study 
Table 3 Frequently used PPE by healthcare professionals before and during COVID-19 $(n=1134)$

\begin{tabular}{|c|c|c|c|c|c|c|}
\hline \multirow{2}{*}{$\begin{array}{l}\text { PPE use by } \\
\text { professional } \\
\text { category } \\
\text { before and } \\
\text { during } \\
\text { COVID-19 }\end{array}$} & \multicolumn{6}{|c|}{ Frequently used PPE, \% } \\
\hline & Glove & Gown & Facemask & N95 respirator & Eye protection & Hair cover \\
\hline \multicolumn{7}{|c|}{ Use by physician $(n=252)$} \\
\hline Before & 94.0 & 66.3 & 48.4 & 15.9 & 17.8 & 11.9 \\
\hline During & 94.8 & 69.0 & 89.7 & 23.0 & 17.1 & 14.7 \\
\hline$P$-value & 0.697 & 0.505 & $<0.001$ & 0.043 & 0.815 & 0.358 \\
\hline \multicolumn{7}{|c|}{ Use by intern $(n=123)$} \\
\hline Before & 91.1 & 62.6 & 36.6 & 3.3 & 4.1 & 4.1 \\
\hline During & 92.7 & 62.6 & 92.7 & 13.0 & 14.6 & 2.4 \\
\hline P-value & 0.641 & 1.00 & $<0.001$ & 0.005 & 0.004 & 0.472 \\
\hline \multicolumn{7}{|c|}{ Use by nurse $(n=453)$} \\
\hline Before & 92.3 & 74.0 & 55.0 & 9.1 & 12.1 & 17.9 \\
\hline During & 91.8 & 71.5 & 82.1 & 22.3 & 24.3 & 22.3 \\
\hline P-value & 0.806 & 0.412 & $<0.001$ & $<0.001$ & $<0.001$ & 0.097 \\
\hline \multicolumn{7}{|c|}{ Use by midwife ( $n=117)$} \\
\hline Before & 95.7 & 67.5 & 41.0 & 5.1 & 16.2 & 22.2 \\
\hline During & 94.0 & 68.4 & 79.5 & 21.4 & 40.2 & 29.9 \\
\hline P-value & 0.553 & 0.889 & $<0.001$ & $<0.001$ & $<0.001$ & 0.180 \\
\hline \multicolumn{7}{|c|}{ Use by others $(n=189)^{\mathrm{a}}$} \\
\hline Before & 81.5 & 79.4 & 37.6 & 6.3 & 4.2 & 7.9 \\
\hline During & 86.2 & 77.8 & 88.4 & 21.2 & 19.0 & 14.3 \\
\hline P-value & 0.208 & 0.707 & $<0.001$ & $<0.001$ & $<0.001$ & 0.049 \\
\hline \multicolumn{7}{|c|}{ Use by all categories $(n=1134)$} \\
\hline Before & 91.1 & 71.3 & 47.2 & 9.1 & 11.6 & 13.8 \\
\hline During & 91.9 & 70.7 & 85.7 & 21.2 & 22.4 & 17.9 \\
\hline$P$-value & 0.498 & 0.781 & $<0.001$ & $<0.001$ & $<0.001$ & 0.008 \\
\hline
\end{tabular}

${ }^{\mathrm{a}}$ Other: Includes anesthetist, pharmacist, health officer, lab technologist and radiographer

hospitals, and $54.7 \%(n=584)$ and $17.5 \%(n=187)$ of the respondents reported that they were unsatisfied or somewhat unsatisfied with the availability of PPE, respectively. Similarly, $48.8 \%(n=521)$ and $20 \%(n=213)$ of the participants self-reported that they were unhappy or somewhat unhappy with the current use of PPE by health professionals in the hospital, respectively. Overall, only $12 \%$ or less of the respondents expressed their opinion that they were satisfied or somewhat satisfied with the current availability or use of PPE at their hospitals.

About 28\% $(n=294)$ and 27\% $(n=291)$ of all the respondents self-reported that they were dissatisfied or strongly dissatisfied, respectively, about the availability of the correct PPE in their hospital, as recommended by WHO, for managing suspected/confirmed COVID-19 patients (Table 5). It is only about one-third of the respondents who agreed or strongly agreed about the availability of PPEs in their hospital for managing
COVID-19 patients as recommended by WHO. Generally, more than half of the different HCP categories reported that they disagreed or strongly disagreed about the statement on the availability of correct PPE in the hospital for managing COVID-19 patients as per the WHO recommendation, ranging from about $51 \%$ by physicians and $66 \%$ by interns. About 54 and $17.5 \%$ of the respondents reported that they were unsatisfied or somewhat unsatisfied with the availability of PPE, respectively. The overwhelming majority of interns (76.8\%), physicians $(72.3 \%)$ and nurses $(72.9 \%)$ were unsatisfied with the current availability of PPE in the study hospitals. Only $10 \%$ of the respondents expressed their opinion that they were satisfied or somewhat satisfied with the current availability of PPE at their hospitals.

This study also assessed the level of preparedness of HCPs to provide direct clinical care to COVID-19 patients. Only 5.2 and $32.8 \%$ of the participants felt they 
Table 4 Use of PPE during last interaction with a patient by healthcare professionals $(n=1080)$

\begin{tabular}{|c|c|c|c|c|c|c|}
\hline \multirow[t]{2}{*}{ Characteristics } & \multicolumn{6}{|c|}{ Last used PPE, \% } \\
\hline & Glove & Gown & Facemask & N95 respirator & Eye protection & Hair cover \\
\hline \multicolumn{7}{|l|}{ Gender } \\
\hline Male & 90.9 & 72.2 & 83.7 & 27.0 & 18.3 & 15.0 \\
\hline Female & 88.5 & 70.1 & 86.7 & 20.1 & 18.7 & 19.4 \\
\hline$P$-value & 0.208 & 0.461 & 0.152 & 0.007 & 0.853 & 0.053 \\
\hline \multicolumn{7}{|l|}{ Professional category } \\
\hline Physician & 93.4 & 68.4 & 89.3 & 24.2 & 14.3 & 12.7 \\
\hline Intern & 94.7 & 65.8 & 94.7 & 21.9 & 15.8 & 5.3 \\
\hline Nurse & 89.5 & 73.1 & 81.3 & 22.4 & 20.1 & 22.4 \\
\hline Midwife & 93.7 & 71.2 & 84.7 & 25.2 & 34.2 & 28.8 \\
\hline Other ${ }^{a}$ & 79.2 & 73.2 & 83.6 & 24.6 & 12.6 & 12.0 \\
\hline$P$-value & $<0.001$ & 0.453 & 0.002 & 0.939 & $<0.001$ & $<0.001$ \\
\hline \multicolumn{7}{|l|}{ Department/Unit } \\
\hline OB/GYN & 96.3 & 70.6 & 87.8 & 19.3 & 24.6 & 20.3 \\
\hline Surgical & 96.0 & 71.3 & 84.0 & 32.0 & 24.0 & 27.3 \\
\hline Pediatrics & 87.3 & 69.0 & 86.6 & 23.2 & 16.2 & 9.2 \\
\hline Medical & 89.9 & 75.5 & 89.9 & 19.4 & 14.4 & 10.8 \\
\hline OPD/Screening/Triage & 79.6 & 75.2 & 80.3 & 22.6 & 15.3 & 11.7 \\
\hline Emergency & 93.4 & 81.3 & 91.2 & 20.9 & 17.6 & 14.3 \\
\hline Anesthesia/OR/IC & 94.3 & 59.2 & 86.4 & 30.7 & 22.7 & 38.6 \\
\hline Other $^{b}$ & 80.8 & 66.4 & 78.1 & 21.9 & 12.3 & 11.6 \\
\hline$P$-value & $<0.001$ & 0.034 & 0.036 & 0.090 & 0.032 & $<0.001$ \\
\hline \multicolumn{7}{|l|}{ Hospital $^{c}$} \\
\hline TASH & 94.7 & 74.2 & 87.5 & 24.2 & 13.6 & 22.0 \\
\hline $\mathrm{ZMH}$ & 85.5 & 62.8 & 84.9 & 14.0 & 12.2 & 13.4 \\
\hline GMH & 93.0 & 79.1 & 91.3 & 8.7 & 20.0 & 16.5 \\
\hline $\mathrm{Y} 12 \mathrm{HMC}$ & 84.5 & 81.1 & 90.5 & 28.4 & 12.8 & 13.5 \\
\hline $\mathrm{MH}$ & 89.4 & 72.0 & 77.0 & 14.3 & 11.8 & 6.8 \\
\hline SPHMMC & 88.6 & 62.3 & 82.3 & 40.9 & 37.3 & 25.5 \\
\hline$P$-value & 0.006 & $<0.001$ & 0.003 & $<0.001$ & $<0.001$ & $<0.001$ \\
\hline Overall use of PPE & 89.6 & 71.1 & 85.3 & 23.4 & 18.5 & 17.3 \\
\hline
\end{tabular}

${ }^{\mathrm{a} O t h e r: ~ I n c l u d e s ~ a n e s t h e t i s t, ~ p h a r m a c i s t, ~ h e a l t h ~ o f f i c e r, ~ l a b ~ t e c h n o l o g i s t ~ a n d ~ r a d i o g r a p h e r ~}$ bOther: Includes Isolation room/ward, Pharmacy, Oncology, etc.

${ }^{\mathrm{C}}$ TASH Tikur Anbessa Specialized Hospital; ZMH Zewditu Memorial Hospital; GMH Ghandi Memorial Hospital; YHMC Yekatit 12 Hospital Medical College; MH Menelik II Hospital; SPHMMC St. Paul Hospital Millennium Medical College.

were completely prepared or somewhat prepared to provide direct clinical care to COVID-19 patients, respectively. Overall, the majority $(77 \%, n=872 / 1134)$ of the participants perceived that the PPE currently available to them at their hospital was inadequate to keep them safe from infection when managing suspected or confirmed COVID-19 patients. The mean and the SD of the satisfaction scores of the four items regarding the availability and use of PPE were calculated. Table 6 shows the degree of satisfaction scores of all respondents. The first two items had a mean score of $<2(1.85 \pm 1.13$ and $1.97 \pm 1.13$ ), indicating strong dissatisfaction of the
HCPs, while the remaining two items had a mean score between 1.5 and $2.0(2.65 \pm 1.40$ and $2.70 \pm 1.39)$, showing the dissatisfaction of the study participants. The overall score was $2.29 \pm 0.97$, showing that about $77 \%$ of the respondents reported that they were dissatisfied with the current availability and use of PPE in the study hospitals.

\section{Bivariate and multivariable analyses of satisfaction level about PPE}

The total satisfaction score regarding the availability and use of PPE for each respondent was used as dependent 
Table 5 Satisfaction level about the availability and use of PPE in the study hospitals by professional category $(n=1067)$

\begin{tabular}{|c|c|c|c|c|c|c|}
\hline \multirow[t]{2}{*}{ Variable } & \multicolumn{5}{|c|}{ Professional category, $\mathrm{n}(\%)$} & \multirow[t]{2}{*}{ Total, n (\%) } \\
\hline & Physician & Intern & Nurse & Midwife & Other $^{\mathrm{a}}$ & \\
\hline \multicolumn{7}{|c|}{ I am satisfied with the current availability of PPE in my hospital during the COVID-19 } \\
\hline Strongly satisfied & $4(1.7)$ & $1(0.8)$ & $8(1.9)$ & $2(1.8)$ & $3(1.7)$ & $18(1.7)$ \\
\hline Satisfied & $18(7.5)$ & $1(0.8)$ & $43(10.2)$ & $13(11.9)$ & $15(8.5)$ & $90(8.4)$ \\
\hline Average & $40(16.7)$ & $26(22.0)$ & $62(14.7)$ & $22(20.2)$ & $38(21.5)$ & $188(17.6)$ \\
\hline Dissatisfied & $54(22.5)$ & $17(14.4)$ & $71(16.8)$ & $18(16.5)$ & $27(15.3)$ & $187(17.5)$ \\
\hline Strongly dissatisfied & $124(51.7)$ & $73(61.9)$ & $239(56.5)$ & $54(49.5)$ & $94(53.1)$ & $584(54.7)$ \\
\hline \multicolumn{7}{|c|}{ I am satisfied with the current use of PPE by health professionals in my hospital } \\
\hline Strongly satisfied & $4(1.7)$ & $1(0.8)$ & $9(2.1)$ & $3(2.8)$ & $4(2.3)$ & $21(2.0)$ \\
\hline Satisfied & $27(11.3)$ & $6(5.1)$ & $42(9.9)$ & $18(16.5)$ & $17(9.6)$ & $110(10.3)$ \\
\hline Average & 39 (16.3) & $26(22.0)$ & $80(18.9)$ & $20(18.3)$ & $37(20.9)$ & $202(18.9)$ \\
\hline Dissatisfied & $77(32.1)$ & $18(15.3)$ & $71(16.8)$ & $17(15.6)$ & $30(16.9)$ & $213(20.0)$ \\
\hline Strongly dissatisfied & $93(38.8)$ & $67(56.8)$ & $221(52.2)$ & $51(46.8)$ & $89(50.3)$ & $521(48.8)$ \\
\hline \multicolumn{7}{|c|}{$\begin{array}{l}\text { I am satisfied that the correct PPE (as recommended by WHO) is always available to me when managing suspected or confirmed COVID } \\
19 \text { patient in my hospital }\end{array}$} \\
\hline Strongly satisfied & $16(6.7)$ & $10(8.5)$ & $65(15.4)$ & $13(11.9)$ & $28(15.8)$ & $132(12.4)$ \\
\hline Satisfied & $73(30.4)$ & $16(13.6)$ & $83(19.6)$ & $22(20.2)$ & $40(22.6)$ & $234(21.9)$ \\
\hline Average & $27(11.3)$ & $13(11.0)$ & $50(11.8)$ & $6(5.5)$ & $20(11.3)$ & $116(10.9)$ \\
\hline Dissatisfied & $54(22.5)$ & $27(22.9)$ & $137(32.4)$ & $34(31.2)$ & $42(23.7)$ & $294(27.6)$ \\
\hline Strongly dissatisfied & 70 (29.2) & $52(44.1)$ & $88(20.8)$ & $34(31.2)$ & $47(26.6)$ & $291(27.3)$ \\
\hline \multicolumn{7}{|c|}{$\begin{array}{l}\text { I am satisfied that the correct PPE (as recommended by WHO) is always available to me when treating non-COVID-19 patients in my } \\
\text { hospital }\end{array}$} \\
\hline Strongly satisfied & $14(5.8)$ & $7(5.9)$ & $63(14.9)$ & $12(11.0)$ & $25(14.1)$ & $121(11.3)$ \\
\hline Satisfied & 79 (32.9) & $20(16.9)$ & $110(26.0)$ & $28(25.7)$ & $44(24.9)$ & $281(26.3)$ \\
\hline Average & $17(7.1)$ & $10(8.5)$ & $845(10.6)$ & $8(7.3)$ & $16(9.0)$ & $96(9.0)$ \\
\hline Dissatisfied & $67(27.9)$ & $32(27.1)$ & $112(26.5)$ & $33(20.3)$ & $46(26.0)$ & $290(27.2)$ \\
\hline Strongly dissatisfied & $63(26.3)$ & $49(41.5)$ & $93(22.0)$ & $28(25.7)$ & $46(26.0)$ & $279(26.1)$ \\
\hline Total, n (\%) & $240(22.5)$ & $118(11.1)$ & 423 (39.6) & 109 (10.2) & 177 (16.6) & $1067(100)$ \\
\hline
\end{tabular}

OOther: Includes anesthetist, pharmacist, health officer, lab technologist and radiographer

Table 6 Descriptive statistics of PPE satisfaction of healthcare professionals ( $n=1067)$

\begin{tabular}{|c|c|c|c|c|c|}
\hline Satisfaction statement & $\begin{array}{l}\text { Mean } \pm \\
\text { SD }\end{array}$ & $\begin{array}{l}\mathrm{Cl} \\
(95 \%)\end{array}$ & $\begin{array}{l}\text { Satisfied } \\
(\%)^{\mathrm{a}}\end{array}$ & $\begin{array}{l}\text { Average } \\
(\%)\end{array}$ & $\begin{array}{l}\text { Dissatisfied } \\
(\%)\end{array}$ \\
\hline Satisfied with the current availability of PPE in my hospital during the COVID-19 & $1.85 \pm 1.13$ & $\begin{array}{l}1.78- \\
1.92\end{array}$ & 10.1 & 17.6 & 72.3 \\
\hline Satisfied with the current use of PPE by HCPs in my hospital & $1.97 \pm 1.13$ & $\begin{array}{l}1.90- \\
2.04\end{array}$ & 12.3 & 18.9 & 68.8 \\
\hline $\begin{array}{l}\text { Satisfied that the correct PPE (as recommended by WHO) is always available to me } \\
\text { when treating a patient with suspected or confirmed COVID-19 in my hospital }\end{array}$ & $2.65 \pm 1.40$ & $\begin{array}{l}2.57- \\
2.73\end{array}$ & 34.3 & 10.9 & 54.8 \\
\hline $\begin{array}{l}\text { Satisfied that the correct PPE (as recommended by WHO) is always available to me } \\
\text { when treating a non-COVID-19 patient in my hospital }\end{array}$ & $2.70 \pm 1.39$ & $\begin{array}{l}2.62- \\
2.78\end{array}$ & 37.7 & 9.0 & 53.3 \\
\hline Overall & $2.29 \pm 0.97$ & $\begin{array}{l}2.23- \\
2.35\end{array}$ & 21.3 & 14.1 & 62.3 \\
\hline
\end{tabular}

aRange from 1 "strongly dissatisfied" to 5 "strongly satisfied" 
variable and dichotomized into two groups: dissatisfied $(<12$ scores) and satisfied ( $\geq 12$ scores). This dependent variable was further subjected to bivariate and multivariable binary logistic regression analyses using potential independent variables.

Table 7 shows the relationship between the respondents PPE satisfaction level and independent factors for both bivariate and multivariable logistic regression analyses. In the bivariate logistic regression, the odds of satisfaction with the availability and use of PPE among was lower among respondents from emergency unit $(\mathrm{OR}=$ 0.49, 95\% CI:0.25-0.99, $P=0.046)$ and anesthesia/OR/IC (OR $=0.46,95 \%$ CI:0.22-0.94, $P=0.033)$. The HCPs at TASH and MH were less likely to be satisfied with the availability and use of PPE in their hospital than those in SPHMMC. However, respondents from GMH and Y12HMC were more satisfied than those from the SPHMMC. The odds of satisfaction among those respondents who reported that PPE was adequately available to protect themselves from the risk of infection when managing suspected or confirmed COVID-19 cases were about five times higher than among those who said 'no' (OR $=5.07,95 \%$ CI:3.66-7.01, $P<0.001)$. The odds of satisfaction among those health workers who reported that they were prepared to provide direct care to suspected or confirmed COVID-19 cases were higher than among other healthcare workers $(\mathrm{OR}=2.01$, 95\% CI:1.47-2.74, $P<0.001$ ).

In the multivariable logistic regression analysis (Table 7), which was performed using eight independent variables in the model, there were significant differences in satisfaction of HCPs according to the hospital, ranging from $\mathrm{MH}(\mathrm{OR}=0.28,95 \% \mathrm{CI}: 0.13-0.22, P=0.001)$ to Y12HMC $(\mathrm{OR}=2.56,95 \% \mathrm{CI}: 1.47-4.45, P=0.001)$, as compared to SPHMMC. The odds of satisfaction among those healthcare workers who reported that PPE was adequately available to protect themselves from the risk of infection when managing suspected or confirmed COVID-19 cases were 7.65 times higher than among those who reported inadequate PPE $(\mathrm{OR}=7.65,95 \% \mathrm{CI}$ : 5.09-11.51, $P<0.001)$. The odds of satisfaction among HCPs who reported that they were prepared to provide direct care to suspected or confirmed COVID-19 cases were higher than other healthcare workers $(\mathrm{OR}=2.07$, 95\% CI:1.42-3.03, $P<0.001)$. The factors such as gender, professional category, training in PPE after COVID-19, and use of any 'homemade', or 'creative' PPE in the hospital did not have significant influence on the satisfaction level of HCPs regarding the availability and use of PPE.

\section{Discussion}

This study aimed to investigate the availability and use of PPE among 1134 HCPs working in six public hospitals during the early stage of COVID-19 in Addis Ababa,
Ethiopia. Our findings showed limited access to appropriate and sufficient PPE to health workers in the care of COVID-19 patients before and during the pandemic. Shortages of appropriate PPE particularly N95 respirator for HCPs irrespective of the hospitals were observed already before COVID-19. This raises a concern regarding the availability and use of proper PPE in the hospitals and the challenges of healthcare workers to combat COVID-19 infection. Despite these concerns, the HCPs continued to work during COVID-19 and they must be equipped with appropriate PPE in order to practice their clinical role with confidence. In the previous studies, inadequate personal protection during the management of suspected or confirmed COVID-19 patients, proximity to patients infected by the virus and prolonged exposure to the infected environment were cited as reasons for the healthcare workers becoming infected with the virus $[16,17]$.

Lack of appropriate PPE itself can put the HCPs at risk of contracting the virus and infecting other healthcare workers and their family. This problem did not only exist in Ethiopia, it was also reported from China [18] and other countries. In one study in Jordan, only 18.5\% of frontline doctors reported that all PPE were available and most shortage was reported in protective facemasks [19]. Several studies emphasized that adequate training, proper use and uninterrupted availability of adequate PPE give HCPs a minimal risk of infection when treating suspected or confirmed cases of COVID-19 [18, 20, 21]. A study in China found that of 420 doctors and nurses deployed to frontline work at Wuhan hospitals between January and April 2020 none of them contracted COVID-19 after being trained in the proper use of N95 respirator, surgical mask, gloves, eye protection and hair covers [22]. Another study from Hong Kong demonstrated that correct use of N95 respirator, gown, gloves, goggles and face shield by healthcare workers was associated with no cases of infection over a 42-day observation period [23]. Studies have also revealed that the risk of SARS-CoV-2 infection is significantly higher particularly among frontline HCPs with inadequate PPE caring for suspected or confirmed COVID-19 patients [24].

The shortage of PPE is particularly concerning for the commonly used N95 respirators. However, recommendations are currently available to use surgical or medical masks when N95 is in short supply [13]. A recent systematic review and meta-analysis showed that medical masks are not inferior to N95 respirators for protecting healthcare workers against viral respiratory infections during routine care and non-aerosol-generating procedures, but the researchers strongly recommended preservation of N95 respirators for high-risk, aerosolgenerating procedures during COVID-19 when its supply is inadequate [25]. In response to the shortage of 
Table 7 Factors associated with satisfaction of healthcare professionals regarding the availability and use of PPE using binary logistic regression analyses $(n=1067)$

\begin{tabular}{|c|c|c|c|c|c|c|}
\hline \multirow[t]{2}{*}{ Predictor } & \multicolumn{2}{|c|}{ Satisfaction level, n (\%) } & \multirow{2}{*}{$\begin{array}{l}\text { Crude } \\
\text { OR }(95 \% \mathrm{Cl})^{\mathrm{a}}\end{array}$} & \multirow{2}{*}{$\begin{array}{l}P \text { - } \\
\text { value }\end{array}$} & \multirow{2}{*}{$\begin{array}{l}\text { Adjusted } \\
\text { OR }(95 \% \mathrm{Cl})\end{array}$} & \multirow{2}{*}{$\begin{array}{l}P \text { - } \\
\text { value }\end{array}$} \\
\hline & $\begin{array}{l}\text { Dissatisfied } \\
\text { (< } 12 \text { scores) }\end{array}$ & $\begin{array}{l}\text { Satisfied } \\
\text { ( } \geq 12 \text { scores) }\end{array}$ & & & & \\
\hline \multicolumn{7}{|l|}{ Gender } \\
\hline Male & $398(78.7)$ & $463(21.3)$ & $1.28(0.95-1.74)$ & 0.110 & $1.32(0.92-1.90)$ & 0.135 \\
\hline Female & $463(82.5)$ & $98(17.5)$ & $1.0^{\mathrm{b}}$ & & 1.0 & \\
\hline \multicolumn{7}{|l|}{ Professional category } \\
\hline Physician & $196(81.7)$ & $44(18.3)$ & 1.0 & & 1.0 & \\
\hline Intern & $106(89.8)$ & $12(10.2)$ & $0.50(0.26-1.00)$ & 0.050 & $0.70(0.32-1.50)$ & 0.356 \\
\hline Nurse & 341 (80.6) & $82(19.4)$ & $1.07(0.71-1.61)$ & 0.740 & $1.06(0.66-1.71)$ & 0.808 \\
\hline Midwife & $81(74.3)$ & $28(25.7)$ & $1.54(0.90-2.64)$ & 0.117 & $1.59(0.76-3.32)$ & 0.224 \\
\hline Other $^{c}$ & $137(77.1)$ & $40(22.6)$ & $1.30(0.80-2.21)$ & 0.284 & $0.76(0.41-1.41)$ & 0.381 \\
\hline \multicolumn{7}{|l|}{ Department/Unit } \\
\hline OB/GYN & $141(76.2)$ & $44(23.8)$ & 1.0 & & 1.0 & \\
\hline Surgical & $126(84.0)$ & $24(16.0)$ & $0.61(0.35-1.06)$ & 0.080 & $0.94(0.44-2.04)$ & 0.879 \\
\hline Pediatrics & $113(80.7)$ & $27(19.3)$ & $0.77(0.45-1.31)$ & 0.332 & $1.02(0.48-2.55)$ & 0.965 \\
\hline Medical & $110(82.7)$ & $23(17.3)$ & $0.67(0.38-1.18)$ & 0.163 & $0.75(0.34-1.64)$ & 0.474 \\
\hline OPD/Screening/Triage & $111(81.6)$ & $25(18.4)$ & $0.72(0.42-1.25)$ & 0.245 & $0.77(0.37-1.61)$ & 0.488 \\
\hline Emergency & $78(86.7)$ & $12(13.3)$ & $0.49(0.25-0.99)$ & 0.046 & $0.44(0.19-1.03)$ & 0.058 \\
\hline Anesthesia/OR/IC & 77 (87.5) & $11(12.5)$ & $0.46(0.22-0.94)$ & 0.033 & $0.61(0.25-1.51)$ & 0.287 \\
\hline Other $^{d}$ & $105(72.4)$ & $40(27.6)$ & $1.22(0.74-2.01)$ & 0.432 & $1.71(0.80-3.68)$ & 0.168 \\
\hline \multicolumn{7}{|l|}{ Hospital $^{\mathrm{e}}$} \\
\hline TASH & $236(87.1)$ & 35 (12.9) & $0.57(0.35-0.93)$ & 0.024 & $0.55(0.31-0.96)$ & 0.035 \\
\hline ZMH & $133(81.6)$ & $30(18.4)$ & $0.87(0.52-1.46)$ & 0.602 & $0.81(0.45-1.47)$ & 0.490 \\
\hline $\mathrm{GMH}$ & $76(67.3)$ & $37(32.7)$ & $1.88(1.13-3.14)$ & 0.015 & $1.52(0.80-2.87)$ & 0.199 \\
\hline Y12HMC & $90(64.2)$ & $50(35.7)$ & $2.14(1.33-3.46)$ & 0.002 & $2.56(1.47-4.45)$ & 0.001 \\
\hline $\mathrm{MH}$ & $152(94.4)$ & $9(5.6)$ & $0.23(0.11-0.48)$ & $<0.001$ & $0.28(0.13-0.62)$ & 0.002 \\
\hline SPHMMC & $174(79.5)$ & $45(20.5)$ & 1.0 & & 1.0 & \\
\hline \multicolumn{7}{|c|}{ Received training in PPE since COVID-19 pandemic } \\
\hline Yes & $328(78.3)$ & $91(21.7)$ & $1.29(0.95-1.75)$ & 0.109 & $1.12(0.78-1.61)$ & 0.542 \\
\hline No & $533(82.3)$ & $115(17.7)$ & 1.0 & & 1.0 & \\
\hline \multicolumn{7}{|c|}{ Reported that PPE was adequately available to protect the risk of coronavirus infection } \\
\hline Yes & $149(58.4)$ & $106(41.6)$ & $5.07(3.66-7.01)$ & $<0.001$ & $7.65(5.09-11.51)$ & $<0.001$ \\
\hline No & $712(87.7)$ & $100(12.3)$ & 1.0 & & 1.0 & \\
\hline \multicolumn{7}{|c|}{ Used any 'homemade', or 'creative' PPE } \\
\hline Yes & $235(81.6)$ & $53(18.4)$ & $0.92(0.65-1.31)$ & 0.649 & $0.65(0.42-1.03)$ & 0.066 \\
\hline No & $626(80.4)$ & $153(19.6)$ & 1.0 & & 1.0 & \\
\hline \multicolumn{7}{|c|}{ Prepared to provide direct care to COVID-19 cases } \\
\hline Yes & $261(73.1)$ & $96(26.9)$ & $2.01(1.47-2.74)$ & $<0.001$ & $2.07(1.42-3.03)$ & $<0.001$ \\
\hline No & $600(84.5)$ & $110(15.5)$ & 1.0 & & 1.0 & \\
\hline Total & $861(80.7)$ & $206(19.3)$ & 1067 & & & \\
\hline
\end{tabular}

adds Ratio and its 95\% Confidence Interval; ${ }^{\text {b }}$ Reference

'Other: Includes anesthetist, pharmacist, health officer, lab technologist and radiographer

dOther: Includes Isolation room/ward, Pharmacy, Oncology, etc.

${ }^{\mathrm{e}}$ TASH Tikur Anbessa Specialized Hospital; ZMH.Zewditu Memorial Hospital; GMH Ghandi Memorial Hospital; Y12HMC Yekatit 12 Hospital Medical College; MH

Menelik II Hospital; SPHMMC St. Paul Hospital Millennium Medical College. 
appropriate PPE, studies showed that the scarcity could be mitigated through proper re-use or extended use [26, 27]. Evidence indicates that N95 respirators maintain their protection when used for extended periods [28] although using them for longer than $4 \mathrm{~h}$ is not recommended due to increased discomfort [28, 29]. The choice of PPE is also dependent on the level of protection provided by PPE and the risk of exposure, thus understanding them is the key in choosing appropriate PPE [30]. In this regard, the WHO IPC recommendations have proven to be an invaluable resource and were quickly adopted and implemented in many countries in preparing their response to the COVID-19 pandemic [31]. As a result, the WHO guidance on the rational use of PPE for COVID-19 has provided appropriate criteria on how to select and use appropriate PPE in different settings when PPE is in short supply [13].

The current study gives a first impression of the satisfaction level of HCPs with regard to the availability and use of proper PPE during the COVID-19 pandemic. The findings show that the HCPs had an overall low level of satisfaction with the availability and use of appropriate PPE in their hospital. The healthcare system, which was already affected by the widespread shortage of HCPs, will be further affected by the dissatisfied health workforce. Currently, there is limited evidence on the satisfaction of healthcare workers about the availability and use of PPE. A recent study conducted in North Shewa Zone of Ethiopia reported that $75 \%$ of the healthcare workers in hospitals felt unsafe about their work environment and only $<30 \%$ reported that they had access to proper PPE in the hospitals [32], which is comparable to our findings.

The multivariable logistic regression analysis showed that the satisfaction of HCPs regarding the availability and use of PPE were affected by different factors, such as hospital, adequate availability of PPE, and preparedness to provide direct care to the suspected or confirmed COVID-19 cases. Among the healthcare workers, those who reported that PPE was adequately available to protect themselves from the risk of infection when managing COVID-19 patients had a significantly higher level of satisfaction about PPE. As there is limited published research on the relationship between healthcare workers satisfaction level with regard to the availability and use of appropriate PPE and associated factors, this study contributes additional knowledge that good availability of PPE is associated with a higher willingness to care for COVID-19 patients.

Finally, this study had some limitations. First, the study might be affected by selection bias and eligible participants who had direct contact with the management of COVID-19 patients might be excluded. Second, the study focused on more general populations of HCPs similar to other studies $[33,34]$ rather than healthcare workers who might have direct contact with COVID-19 patients [35]. Relying solely on respondents to determine the availability and use of PPE can introduce recall bias. Lastly, the results of this study are based on a selfreported questionnaire using a cross-sectional design, and the self-reported response might not adequately represent the true situation. Despite these limitations, the results obtained provide important information to guide the efforts to avail appropriate PPE and optimize its use for effectively reducing the risk of COVID-19 infection among HCPs through implementing appropriate IPC measures.

\section{Conclusions}

In conclusion, this study has illuminated the level of the availability and use of PPE by HCPs working at hospitals, and identified a critical shortage of appropriate PPE both before and during COVID-19. The availability of N95 respirator was particularly insufficient, and the use of goggles and gowns were unsatisfactory, which might increase the risk of COVID-19 infection among HCPs. The study shows that the HCPs had an overall low level of satisfaction with the current availability and use of PPE in their hospital, which might potentially lead to a lower level of preparedness and readiness among health workers to fight against COVID-19 infection. With the current critical shortages of PPE in hospitals, the ongoing widespread COVID-19 pandemic in Ethiopia could result in devastating consequences. The findings provide considerable insights into the importance of urgent need and concerted efforts to adequately supply the healthcare facilities with appropriate PPE to alleviate the current challenges during the COVID-19 pandemic. Preventing the risks of COVID-19 infection among HCPs through providing proper and adequate PPE should be strengthened and needs to be a top priority for Ministry of Health and the Government of Ethiopia.

\section{Abbreviations \\ AAU: Addis Ababa university; Cl: Confidence interval; COVID-19: Coronavirus disease 2019; CSPro: Census surveys professional; EPHI: Ethiopian public health institute; GMH: Ghandi memorial hospital; HCPs: Healthcare professionals; IRB: Institutional review board; MH: Menelik II hospital; MoH: Ministry of health; OPD: Outpatient department; IPC: Infection prevention and control; PPE: Personal protective equipment; SARS-CoV- 2: Severe acute respiratory syndrome coronavirus 2; SD: Standard deviation; SPH: School of public health; SPHMMC: St. Paul hospital millennium medical college; SPSS: Statistical package for social sciences; TASH: Tikur anbessa specialized hospital; WHO: World health organization; Y12HMC: Yekati 12 hospital medical college; ZMH: Zewditu memorial hospital}

\section{Supplementary Information}

The online version contains supplementary material available at https://doi. org/10.1186/s13690-021-00668-3.

Additional file 1:. Questionnaires for assessment of the availability and utilization of PPE healthcare professionals in public hospitals in Addis Ababa, June 2020. 
Additional file 2:. Guidelines for data collectors and supervisors of selfadministered questionnaires at public hospitals in Addis Ababa, June 2020.

\section{Acknowledgements}

The authors are grateful to the research staff at the College of Health Sciences of Addis Ababa University. The authors are also grateful to the participating hospitals and their healthcare staff for committing their time and voluntarily for contributing to the research. They are also thankful to all data collectors for their time and commitment.

\section{Authors' contributions}

WD, AW, WAA and WA conceptualized and designed the study. MG, WD and AW supervised the field data collection. WD prepared the final dataset for analysis. WD and AW analyzed and interpreted the data. WD drafted the manuscript. AW provided intellectual role in improving the manuscript. AW, $M G, W A A$ and WA provided major roles in revising the manuscript. All authors read and approved the final manuscript.

\section{Funding}

This study was funded by Addis Ababa University (AAU) and partly supported by the School of Public Health. WD, AW, WAA and WA received the award from the University (RD/LT-312/2020). The funder had no role in the design of the study and collection, analysis, and interpretation of data and in writing the manuscript.

\section{Availability of data and materials}

The datasets used and analyzed during the current study will be available from the corresponding author on reasonable request.

\section{Declarations}

\section{Ethical approval and consent to participate}

Ethical approval was obtained from the Institutional Review Board (IRB) of the College of Health Sciences at Addis Ababa University (protocol number: 042/20/SPH). Written informed consent was obtained from all study participants. All methods were performed in accordance with the relevant guidelines and regulations set out in the Declaration of Helsinki.

\section{Consent for publication}

Not applicable.

\section{Competing interests}

The authors declare that they have no competing interests.

\section{Author details}

'Department of Preventive Medicine, School of Public Health, College of Health Sciences, Addis Ababa University, Addis Ababa, Ethiopia. ${ }^{2}$ Department of Pediatrics and Child Health, School of Medicine, College of Health Sciences, Addis Ababa University, Addis Ababa, Ethiopia. ${ }^{3}$ Department of Internal Medicine, School of Medicine, College of Health Sciences, Addis Ababa University, Addis Ababa, Ethiopia.

\section{Received: 22 March 2021 Accepted: 1 August 2021}

\section{Published online: 17 August 2021}

\section{References}

1. World Health Organization. Statement on the second meeting of the International Health Regulations (2005) Emergency Committee regarding the outbreak of novel coronavirus (2019-nCoV). 2020. https://www.who.int/ news-room/detail/30-01-2020-statement-on-the-second-meeting-of-theinternational-healthregulations-(2005)-emergency-committee-regarding-theoutbreak-of-novelcoronavirus-(2019-ncov). Accessed 15 Aug 2020.

2. Worldometers. COVID-19 Virus Pandemic (Live). https://www.worldometers. info/coronavirus/. 2021. Last updated: July 15, 2021, 08:23 GMT.

3. Ethiopian Public Health Institute. National Public Health Emergency Operation Center. COVID-19 Pandemic Preparedness and Response. Bulletin No. 51, April 23, 2021. Addis Ababa, Ethiopia. Available: https://www. ephigovet/images/novel_coronavirus/EPHI_PHEOC_COVID-19 Weeklybulletin_51_English_05042020.pdf. Accessed 16 June 2021.
4. Bielicki JA, Duval X, Gobat N, Goossens H, Koopmans M, Tacconelli E, van der Werf S Monitoring approaches for health-care workers during the COVID-19 pandemic. Lancet Infect Dis 2020. Published Online July 23, 2020. https://doi.org/10.1016/S1473-3099(20)30458-8, 10, e267.

5. Chersich MF, Gray G, Fairlie L, Eichbaum Q, Mayhew S, Allwood B, English R, Scorgie F, Luchters S, Simpson G, Haghighi MM, Pham MD, Rees H COVID19 in Africa: care and protection for frontline healthcare workers. Glob Health 2020; 16(1):46. https://doi.org/10.1186/s12992-020-00574-3.

6. Mhango M, Dzobo M, Chitungo I, Dzinamarira T. COVID-19 risk factors among health workers: a rapid review. Saf Health Work. 2020;11(3):262-5. https://doi.org/10.1016/j.shaw.2020.06.001.

7. Sua'rez-Garci'a I, Lopez MJM, Vicente AS, Abascal PL. SARS-CoV-2 infection among healthcare workers in a hospital in Madrid, Spain. J Hosp Infect 2020;106(2):357-363. https://doi.org/10.1016/j.jhin.2020.07.020.

8. Ali S, Noreen S, Farooq I, Bugshan A, Vohra F. Risk Assessment of Healthcare Workers at the Frontline against COVID-19. Pak J Med Sci. 2020;36(COVID19S4):COVID19-S99-S103. https://doi.org/10.12669/pjms.36.COVID19-S4.2790.

9. Hussain ZB, Shoman H, Yau PWP, Thevendran G, Randelli F, Zhang M, Kocher MS, Norrish A, Khanduja V. Protecting healthcare workers from COVID-19: learning from variation in practice and policy identified through a global cross-sectional survey. Bone Joint Open. 2020;1-5:144-151. https:// doi.org/10.1302/2046-3758.15.BJO-2020-0024.R1, 5.

10. The COVID-19 Task force of the Department of Infectious Diseases and the IT Service Istituto Superiore di Sanità. Integrated surveillance of COVID-19 in Italy. https://www.epicentro.iss.it/en/coronavirus/bollettino/Infografica_17a prile\%20ENG.pdf. Updated 17 April 2020. Accessed 28 Aug 2020.

11. CDC COVID-19 Response Team. Characteristics of healthcare personnel with COVID-19-United States, February 12-April 9, 2020. Morb Mortal Wkly Rep. 2020;69(15):477-81. https://doi.org/10.15585/mmwr.mm6915e6.

12. Siegel JD, Rhinehart $E$, Jackson $M$, Chiarelho $L$, and the Healthcare Infection Control Practices Advisory Committee, 2007 Guideline for isolation precautions: preventing transmission of infectious agents in healthcare settings. Available at http://www.cdc.gov/hicpac/pdf/isolation/Isolation2007. pdf (accessed June 2020).

13. World Health Organization. Rational use of personal protective equipment for coronavirus disease (COVID-19) and considerations during severe shortages. Interim guidance. WHO, Geneva, April 2020b. Available from: https://www.who.int/publications.

14. CSA. Population Projections for Ethiopia 2007-2037. 2013, Addis Ababa, Ethiopia.

15. Ethiopian Public Health Institute. National Public Health Emergency Operation Center (NPHEOC). COVID-19 Pandemic Preparedness and Response. Bulletin No. 23, October 2020. Addis Ababa, Ethiopia. Available: https://www.ephigovet/images/novel_coronavirus/EPHI_PHEOC_COVID-19_ Weekly-bulletin_23_English_05042020.pdf. Accessed 16 June 2021.

16. Maleki S, Najafi F, Farhadi K, Fakhri M, Husseini F, Naderi M. Knowledge, attitude and behavior of health Care Workers in the Prevention of COVID-19. Res Square 2020. https://doi.org/10.21203/rs.3.rs-23113/v1.

17. Zhu N, Zhang D, Wang W, Li X, Yang B, Song J, et al. A novel coronavirus from patients with pneumonia in China, 2019. N Engl J Med. 2020;382(8): 727-33. https://doi.org/10.1056/NEJMoa2001017.

18. Wang W, Min YZ, Yang CM, et al. Association of personal protective equipment use with successful protection against covid-19 infection among health care workers. medRxiv. 2020.04.24.20070169. [Preprint.]. https://doi. org/10.1101/2020.04.24.20070169.

19. Suleiman A, Bsisu I, Guzu H, Santarisi A, Alsatari M, Abbad A, et al. Preparedness of frontline doctors in Jordan healthcare facilities to COVID-19 outbreak. Int J Environ Res Public Health. 2020;17(9):3181. https://doi.org/1 0.3390/ijerph17093181.

20. Adams JG, Walls RM. Supporting the healthcare workforce during the COVID-19 global epidemic. JAMA. 2020;323(15):1439-40. https://doi.org/10.1 001/jama.2020.3972.

21. Karlsson U, Fraenkel CJ. Complete protection from Covid-19 is possible for health workers. BMJ. 2020;370:m2641 https://doi.org/10.1136/bmj.m2641.

22. Liu M, Cheng SZ, Xu KW, Yang Y, Zhu QT, Zhang H, et al. Use of personal protective equipment against coronavirus disease 2019 by healthcare professionals in Wuhan, China: cross sectional study. BMJ. 2020;369:m2195. https://doi.org/10.1136/bmj.m2195 pmid: 32522737.

23. Cheng VCC, Wong SC, Chen JHK, Yip CCY, Chuang WWM, Tsang OTY, Sridhar $\mathrm{S}$, Chan JFW, Ho PL, Yuen KY Escalating infection control response to the rapidly evolving epidemiology of the coronavirus disease 2019 (COVID-19) 
due to SARS-CoV-2 in Hong Kong. Infect Control Hosp Epidemiol. 2020;5. https://doi.org/10.1017/ice.2020.58, 5, 493, 498

24. Nguyen LH, Drew DA, Joshi AD, Guo CG, Ma W, Mehta RS. Risk of COVID-19 among frontline healthcare workers and the general community: a prospective cohort study. Lancet Public Health 2020. Published Online July 31, 2020. https://doi.org/10.1016/S2468-2667(20)30164-X, 9, e483.

25. Bartoszko JJ, Faroogi MAM, Alhazzani W, Loeb M. Medical masks vs N95 respirators for preventing COVID-19 in healthcare workers: a systematic review and meta-analysis of randomized trials. Influenza Other Respir Viruses. 2020;14(4):365-73. https://doi.org/10.1111/irv.12745.

26. Boškoski I, Gallo C, Wallace M, Costamagna G. COVID-19 pandemic and personal protective equipment shortage: protective efficacy comparing masks and scientific methods for respirator reuse. Gastrointest Endosc. 2020; 92(3):519-23. https://doi.org/10.1016/j.gie.2020.04.048.

27. Czubryt MP, Stecy T, Popke E, Aitken R, Jabusch K, Pound R, Lawes P. Ramjiawan B, Pierce GN N95 mask reuse in a major urban hospital: COVID19 response process and procedure. J Hosp Infect. 2020;106(2):277-282. https://doi.org/10.1016/j.jhin.2020.07.035.

28. Fisher EM, Shaffer RE. Commentary considerations for recommending extended use and limited reuse of filtering Facepiece respirators in health care settings. J Occup Environ Hyg. 2014;11(8):D115-28. https://doi.org/10.1 080/15459624.2014.902954

29. Radonovich $L J \mathrm{Jr}$, Cheng J, Shenal BV, Hodgson M, Bender BS. Respirator tolerance in health care workers. JAMA. 2009;301(1):36-8. https://doi.org/1 0.1001/jama.2008.894.

30. Park SH. Personal protective equipment for healthcare workers during the COVID-19 pandemic. Infect Chemother. 2020;52(2):165-182. https://doi.org/1 0.3947/ic.2020.52.2.165.

31. World Health Organization. Infection prevention and control during health care when coronavirus disease (COVID-19) is suspected or confirmed: Interim guidance. WHO, Geneva. June 2020c. Available from https:/www. who.int/publications/i/item/WHO-2019-nCoV-IPC-2020.4. https://doi.org/1 0.1186/s12992-020-00574-3, 2020

32. Mulu GB, Kebede WM, Worku SA, Mittiku YM, Ayelign B. Preparedness and responses of healthcare providers to combat the spread of COVID-19 among north Shewa zone hospitals, Amhara, Ethiopia, 2020. Infect Drug Resist. 2020;13:3171-8. https://doi.org/10.2147/IDR.S265829 PMID: 33061469.

33. Huynh G, Nguyen TNH, Tran VK, Vo KN, Vo VT, Pham LA. Knowledge and attitude toward COVID-19 among healthcare workers at district 2 hospital, ho chi minh city. Asian Pac J Trop Med. 2020;13(6):260-5, 20200601. https:// doi.org/10.4103/1995-7645.280396.

34. Zhang M, Zhou M, Tang F, Wang Y, Nie H, Zhang L, et al. Knowledge, attitude, and practice regarding COVID-19 among healthcare workers in Henan, China. J Hosp Infect. 2020;105(2):183-7. https://doi.org/10.1016/j. jhin.2020.04.012.

35. Elhadi M, Msherghi A, Alkeelani M, Zorgani A, Zaid A, Alsuyihili A, et al. Assessment of healthcare workers' levels of preparedness and awareness regarding COVID-19 infection in low-resource settings. Am J Trop Med Hyg. 2020;103(2):828-33. https://doi.org/10.4269/ajtmh.20-0330.

\section{Publisher's Note}

Springer Nature remains neutral with regard to jurisdictional claims in published maps and institutional affiliations.

Ready to submit your research? Choose BMC and benefit from:

- fast, convenient online submission

- thorough peer review by experienced researchers in your field

- rapid publication on acceptance

- support for research data, including large and complex data types

- gold Open Access which fosters wider collaboration and increased citations

- maximum visibility for your research: over $100 \mathrm{M}$ website views per year

At BMC, research is always in progress.

Learn more biomedcentral.com/submissions 